\title{
Does Diabetes Double the Risk of Depression?
}

Patrick J. O'Connor, MD, MPH

A. Lauren Crain, $P b D$

William A. Rush, PbD

Ann M. Hanson, BS

Lucy Rose Fischer, PbD

Jobn C. Kluznik, MD

HealthPartners Research Foundation, Minneapolis, Minnesota
Conflicts of interest: none reported

\section{CORRESPONDING AUTHOR}

Patrick J. O'Connor, MD, MPH

HealthPartners Research Foundation 8170 33rd Ave S, MS 21111R

Bloomington, MN 55425

Patrick.J.OConnor@healthpartners.com

\begin{abstract}
PURPOSE In this study, we compared the rate of depression diagnoses in adults with and without diabetes mellitus, while carefully controlling for number of primary care visits.
\end{abstract}

METHODS We matched adults with incident diabetes $(n=2,932)$ or prevalent diabetes $(n=14,144)$ to nondiabetic control patients based on (1) age and sex, or (2) age, sex, and number of outpatient primary care visits. Logistic regression analysis was used to assess the association between various predictors and a diagnosis of depression in each diabetes cohort relative to matched nondiabetic control patients.

RESULTS With matching for age and sex alone, patients with prevalent diabetes having few primary care visits were significantly more likely to have a new depression diagnosis than matched control patients (odds ratio $[\mathrm{OR}]=1.46,95 \%$ confidence interval $[\mathrm{Cl}], 1.19-1.80)$, but this relationship diminished when patients made more than 10 primary care visits $(\mathrm{OR}=0.95,95 \% \mathrm{Cl}, 0.77-1.17)$. With additional matching for number of primary care visits, patients with prevalent diabetes mellitus with few primary care visits were more likely to have a new diagnosis of depression than those in control group $(\mathrm{OR}=1.32,95 \% \mathrm{Cl}, 1.07-1.63)$, but this relationship diminished and reversed when patients made more than 4 primary care visits $(\mathrm{OR}=0.99,95 \% \mathrm{Cl}, 0.80-1.23)$. Similar results were observed in the subset of patients with incident diabetes and their matched control patients.

CONCLUSIONS Patients with diabetes have little or no increase in the risk of a new diagnosis of depression relative to nondiabetic patients when analyses carefully control for the number of outpatient visits. Studies showing such an association may have inadequately adjusted for comorbidity or for exposure to the medical care system.

Ann Fam Med 2009;7:328-335. doi:10.1370/afm.964.

\section{INTRODUCTION}

$\mathrm{D}$ iabetes is a serious chronic disease that leads to a substantial reduction in life expectancy, decreased quality of life, and increased costs of care. Clinical trials demonstrate that adequate glycemic control, ${ }_{1}$ blood pressure control, ${ }^{2}$ lipid control, ${ }^{3}$ aspirin use, and smoking cessation, and physical activity substantially reduce microvascular complications (affecting the eye, foot, and kidney), macrovascular complications (heart attack and stroke), or both in patients with type 1 and type 2 diabetes. ${ }^{4}$

Depression is also a serious chronic disease that is associated with more functional disability than many other chronic diseases. The spectrum of depressive disorders ranges from subsyndromal depressive conditions to major depressive disorder. Previous work on the relationship of diabetes

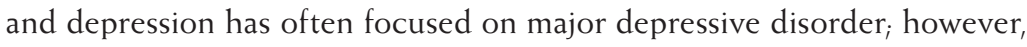
subsyndromal depressive conditions are far more prevalent than major depressive disorder and are linked to increased disability, risk of health decline, and health care use, and premature mortality. ${ }^{5-9}$

Lack of adequate understanding of the relationship between diabetes and depression is a problem that has major clinical and policy implica- 
tions. In a meta-analysis of 42 studies, Anderson et a $1^{10}$ concluded that "the presence of diabetes doubles the odds of having depression." The prevalence of depression varied across studies depending on sex, age, study site, and method of depression ascertainment, but the increased odds ratio for depression in patients with diabetes remained comparable across samples, even accounting for variation in prevalence rates.

A recent study estimated that the relative hazard of depression in patients with untreated diabetes was 0.75 , whereas the likelihood of depression in patients with treated diabetes was $1.54 .^{11}$ This analysis did not adjust for number of visits-a variable that may be associated both with diabetes and with the likelihood of identification and treatment of depression. Robinson et a ${ }^{12}$ compared diabetic and nondiabetic samples of patients in Great Britain and found no clear relationship between onset of diabetes and depression. Another study of elderly patients with type 2 diabetes and a nondiabetic control group found a similar prevalence of depression symptoms in the 2 samples, but also that diabetic patients had more severe depressive symptoms than their counterparts without diabetes. ${ }^{13}$

We conducted this study to extend our understanding of the relationship of depression to diabetes. We considered the limitations of previous work and designed a prospective study that carefully adjusted for patient exposure to the medical care system.

\section{METHODS}

This historical cohort analysis of patients with a new (incident) or existing (prevalent) diabetes diagnosis and matched nondiabetic control patients during the study years 1997-2003 was designed to determine whether diabetes is associated with the likelihood of a subsequent diagnosis of depression.

The project was reviewed in advance, approved, and monitored by the HealthPartners Institutional Review Board (project number 03-010).

\section{Study Site}

The study was conducted at HealthPartners Medical Group (HPMG), a large multispecialty medical group in Minnesota that provided care to an estimated 225,000 patients from 1997 to 2003. All study patients were enrolled in a single health plan, and most care was provided by HPMG at 20 clinics by primary care physicians including family physicians and general internists who deliver care for both diabetic and nondiabetic patients. Previous studies have provided additional detail about patterns of diabetes and depression care in the study population, and more description of the delivery system. ${ }^{14,15}$

\section{Identification of Incident and Prevalent Diabetes Cohorts}

To identify adults with a diagnosis of diabetes mellitus, we first identified all adults who received care in each calendar year from 1997 to 2003 . Each adult was then categorized in each study year as having diabetes if, in addition to being enrolled in the health plan in the 2 previous years, either of 2 criteria were met in that year: (1) the patient made 1 or more inpatient, or 2 or more outpatient visits having International Classification of Diseases, Ninth Revision (ICD-9) codes for diabetes (250.xx) or (2) the patient filled a prescription for a diabetes-specific drug other than metformin. Metformin use required 1 or more accompanying inpatient or outpatient ICD-9 codes for diabetes mellitus because it is prescribed for conditions other than diabetes. Patients with a diagnosis specific to gestational diabetes were excluded.

This study was limited to the population of enrollees aged 40 years and older so that nearly all of the incident cases of diabetes, and the great majority of prevalent cases, would have type 2 diabetes mellitus. ${ }^{16}$ Differences in the epidemiology and clinical presentation of depression by age also support the decision to limit the age range of study subjects.

\section{Incident Diabetes Cohort}

For each patient identified as having diabetes in at least 1 study year, we identified the earliest study year (index year) in which there was evidence of diabetes and assigned an index date that represented the first encounter associated with a diagnosis of diabetes in the index year. Diabetic patients were retained in the incident diabetes cohort if, on further review of data from the 2 years antecedent to the index year, there was no evidence of diabetes as defined by 1 or more diagnostic codes for diabetes mellitus, a filled prescription for any diabetes-specific medication, or laboratory test data that suggested diabetes (fasting plasma glucose level $>125 \mathrm{mg} / \mathrm{dL}$, glycated hemoglobin $\left[\mathrm{A}_{\mathrm{cc}}\right]$ value $>6.1 \%$, or random plasma glucose value $>199 \mathrm{mg} / \mathrm{dL}$ ). This process resulted in a sample of 2,932 patients in the incident diabetes cohort in the index years 1997-2003.

\section{Prevalent Diabetes Cohort}

For each patient identified as having diabetes in at least 1 study year, we randomly selected 1 of the years in which they were identified as having diabetes and designated this as the index year. One calendar date was selected at random within the index year and designated as the index date. This process resulted in a sample of 14,144 patients with prevalent diabetes in the index years 1997-2003. For 1,746 of these patients, the randomly selected index year was also the year of diagnosis (ie, the incident year). We flagged these patients 
so that we could model incident and prevalent cases separately in the analyses.

\section{Identification of Matched Nondiabetic Control Patients}

We matched each patient in the incident and prevalent diabetes cohorts to 2 patients without evidence of diabetes. The first matched patient was randomly selected from patients who were enrolled during the index year and were born within 1 year and were of the same sex as the diabetic patient, but did not have diabetes during the index year or the previous year. The second matched patient was randomly selected from patients who met each of these criteria but who also had the same number of primary care visits in the 2 years after the index date. Because of the difficulty in matching on primary care visits, we ran the matching algorithm in 3 steps. First, diabetic patients with 0 to 5 primary care visits were matched to nondiabetic control patients with precisely the same number of postindex visits. Second, the matches for patients with 6 to 14 visits were allowed to have the same number of visits plus or minus 1 visit. Third, the matches for patients with 15 or more visits had the same number plus or minus 5 visits. This process resulted in slightly fewer control patients matched for age, sex, and visits, with slight differences in the proportion of men and the average number of postindex visits across samples. These same procedures were repeated to assign separate agesex-matched and age-sex-visit-matched nondiabetic patients to each diabetic patient.

\section{Data Sources}

We used automated clinical and administrative databases at HPMG to extract all data needed for this study. The databases included both inpatient and outpatient primary and specialty care, including all mental health services and mental health diagnoses. Previous work indicates that about $95 \%$ of all allopathic medical care used by HPMG members is delivered at HPMG facilities.

\section{Definitions of Variables Depression Diagnosis}

The primary outcome variable was a new diagnosis of depression in the 2 years after the index date, regardless of whether the diagnosis occurred in the first or second year. A new depression diagnosis was operationally defined as the presence of (1) 1 or more inpatient or 2 or more outpatient ICD-9 codes of 311 or 296.3x for depression, or (2) 1 or more outpatient ICD9 codes for depression in addition to a filled prescription for a therapeutic dose of an antidepressant medication, and (3) no evidence of depression before the index date. Prior evidence of depression was defined as
(1) 1 or more ICD-9 codes for depression in the 6 preindex months or (2) 1 or more filled prescriptions for a therapeutic dose of an antidepressant medication in the 6 pre-index months and 1 or more ICD-9 codes for depression in the 12 pre-index months. We considered only ICD-9 codes associated with visits or physician encounters in the calculation of depression diagnosis.

\section{Diabetes Diagnosis}

The primary predictor in these analyses was the diabetes status of patients. In the incident diabetes models, we compared patients in the incident cohort with their nondiabetic control patients matched for age and sex, and matched for age, sex, and visits. In the prevalent diabetes models, we compared patients in the prevalent cohort with their nondiabetic control patients matched for age and sex, and matched for age, sex, and visits, with flagging of prevalent patients captured in their incident year so that they could be modeled separately.

\section{Covariates}

Characteristics that could be related to the likelihood of a depression diagnosis or moderate the relationship between diabetes status and a depression diagnosis were included as covariates, moderators, or both in the analyses. These included age at index date and sex of each study patient and the number of primary care visits the patient had during the 2-year postindex period. We recoded patients with more than 20 visits during this period ( $2 \%-3 \%$ of patients in each cohort) as having had 20 visits to reduce the disproportionate influence of outlying observations. Diagnostic codes, excluding diabetes-related codes, recorded in the 1 year before the index date were used to calculate a Charlson comorbidity score for each patient. ${ }^{17}$ The Charlson score sums points assigned to a patient for specific serious comorbidities such as heart disease, congestive heart failure, and certain cancers. We dichotomized Charlson scores into values of 0 or at least 1 because only a small proportion of patients had a score greater than 0 . Study inclusion criteria required 2 years of continuous health plan enrollment before the index date but no minimum enrollment thereafter. We defined a covariate to identify patients who were enrolled for 19 or fewer of the 24 possible postindex months.

\section{Plan of Analysis}

We used logistic regression analysis to predict the presence of a new depression diagnosis in the at-risk period after the index date from diabetes status, controlling for age at index date (linear and quadratic effects), sex (male, reference $=$ female), number of primary care visits in the at-risk period, Charlson score in the 1-year before the index date $(\geq 1$, reference $=0)$, and months of 
enrollment in the 2 years after the index date $(\leq 19$, reference $=\geq 20$ ). Separate logistic regression models were run on data from the incident and prevalent diabetic cohorts. Each group of diabetic patients was compared with 2 control groups of patients without any evidence of diabetes in the 2 years before the index date: those who were matched on index year, age at index date, and sex (the first control group) and those who were matched on index year, age at index date, sex, and number of primary care visits in the 2 years after the index date (the second control group). Age at index date was centered around the mean age in each group of diabetic patients (57 years in the incident cohort, 61 years in the prevalent cohort), and number of primary care visits was centered around the median value of 6 visits in both diabetic patient groups. We performed bivariate comparisons using $t$ tests and $\chi^{2}$ statistics, as appropriate. Preliminary logistic regression models included the primary predictor, main effects for all covariates, 2-way interactions between the primary predictor and each covariate, and 2-way interactions among the covariates. We retained in the final model the primary predictor and covariate main effects and also the 2 -way interactions that were significant at $P<.05$ and had an odds ratio $(\mathrm{OR})$ of 0.97 or less or 1.03 or greater.

\section{RESULTS}

Among the 14,144 patients with prevalent diabetes, $52 \%$ were male and the average age was 61 years at the index date (Table 1). For about $12 \%$ of this cohort, the index year represented their year of diagnosis (ie, incident year). Relative to the nondiabetic patients matched for age and sex and the nondiabetic patients matched for age, sex, and visits, the patients with prevalent diabetes had more primary care visits in the 2 years after their index date $(P<.001)$ and were more likely to have a Charlson comorbidity score of at least $1(P<.001)$ and to be less than fully enrolled in the postindex period $(P<.001)$. The unadjusted rate of depression in diabetic patients was not higher than that of the patients matched for age, sex, and visits.

Among the 2,932 patients with incident diabetes, $53 \%$ were male and the average age was 57 years at the index date (Table 2). Relative to the nondiabetic patients matched for age and sex, the patients with incident diabetes had more primary care visits in the 2 years after their index date $(P<.001)$ and were more likely to have a Charlson score of at least $1(P<.001)$ and to be fully enrolled in the postindex period $(P<.001)$. Relative to the nondiabetic patients matched for age, sex, and visits, the patients with incident diabetes had more primary care visits in the 2 years after their index date $(P<.001)$ and were more likely to have a Charlson score of at least $1(P<.001)$.

The logistic regression analysis predicting a new depression diagnosis among the patients with prevalent diabetes relative to the age-sex-matched nondiabetic patients showed that the relationship between a patient's diabetes status and depression varied with the number of primary care visits in the at-risk period, $\left(\chi_{2}^{2}=24.85, P<.001\right)$ (Figure 1 and Table 3$)$. The likelihood of a new depression diagnosis decreased as the number of primary care visits increased in all groups. After matching for age and sex alone, patients with prevalent diabetes having few primary care visits were
Table 1. Characteristics of Patients With Prevalent Diabetes and Matched Nondiabetic Patients

\begin{tabular}{|c|c|c|c|}
\hline \multirow[b]{2}{*}{ Characteristic } & \multirow{2}{*}{$\begin{array}{c}\text { Diabetic } \\
\text { Patients } \\
(n=14,144)\end{array}$} & \multicolumn{2}{|c|}{ Nondiabetic Patients Matched for: } \\
\hline & & $\begin{array}{l}\text { Age and Sex } \\
(n=14,144)\end{array}$ & $\begin{array}{l}\text { Age, Sex, and Visits } \\
(n=13,962)\end{array}$ \\
\hline Age, mean (SE), years & $61.0(0.12)$ & $61.0(0.12)$ & $60.9(0.12)$ \\
\hline Male, \% & 51.9 & 51.9 & 51.7 \\
\hline $\begin{array}{l}\text { Number of primary care } \\
\text { visits, mean (SE) }\end{array}$ & $6.7(0.04)$ & $4.5(0.04)^{a}$ & $6.4(0.05)^{a}$ \\
\hline Comorbidity score $\geq 1, \%$ & 15.4 & $9.9^{a}$ & $11.6^{\mathrm{a}}$ \\
\hline Enrollment $\leq 19$ months, $\%$ & 24.2 & $19.5^{\mathrm{a}}$ & $16.6^{\mathrm{a}}$ \\
\hline New depression diagnosis, \% & 7.9 & 5.5 & 8.6 \\
\hline
\end{tabular}

Table 2. Characteristics of Patients With Incident Diabetes and Matched Nondiabetic Patients

\begin{tabular}{|c|c|c|c|}
\hline \multirow[b]{2}{*}{ Characteristic } & \multirow{2}{*}{$\begin{array}{c}\text { Diabetic } \\
\text { Patients } \\
(n=2,932)\end{array}$} & \multicolumn{2}{|c|}{ Nondiabetic Patients Matched for: } \\
\hline & & $\begin{array}{l}\text { Age and Sex } \\
(n=2,932)\end{array}$ & $\begin{array}{l}\text { Age, Sex, and Visits } \\
(\mathrm{n}=2,921)\end{array}$ \\
\hline Age, mean (SE), years & $56.6(0.28)$ & $56.6(0.28)$ & $56.6(0.28)$ \\
\hline Male, \% & 52.7 & 52.7 & 52.6 \\
\hline $\begin{array}{l}\text { Number of primary care } \\
\text { visits, mean (SE) }\end{array}$ & $6.8(0.11)$ & $3.8(0.08)^{a}$ & $6.3(0.10)^{a}$ \\
\hline Comorbidity score $\geq 1, \%$ & 12.4 & $7.0^{\mathrm{a}}$ & $8.2^{\mathrm{a}}$ \\
\hline Enrollment $\leq 19$ months, \% & 17.8 & $23.7^{\mathrm{a}}$ & 17.2 \\
\hline New depression diagnosis, \% & 9.4 & 5.7 & 8.6 \\
\hline
\end{tabular}


Figure 1. Predicted likelihood of a new depression diagnosis among diabetic patients and nondiabetic patients matched for age and sex $(\mathrm{N}=28,288)$.

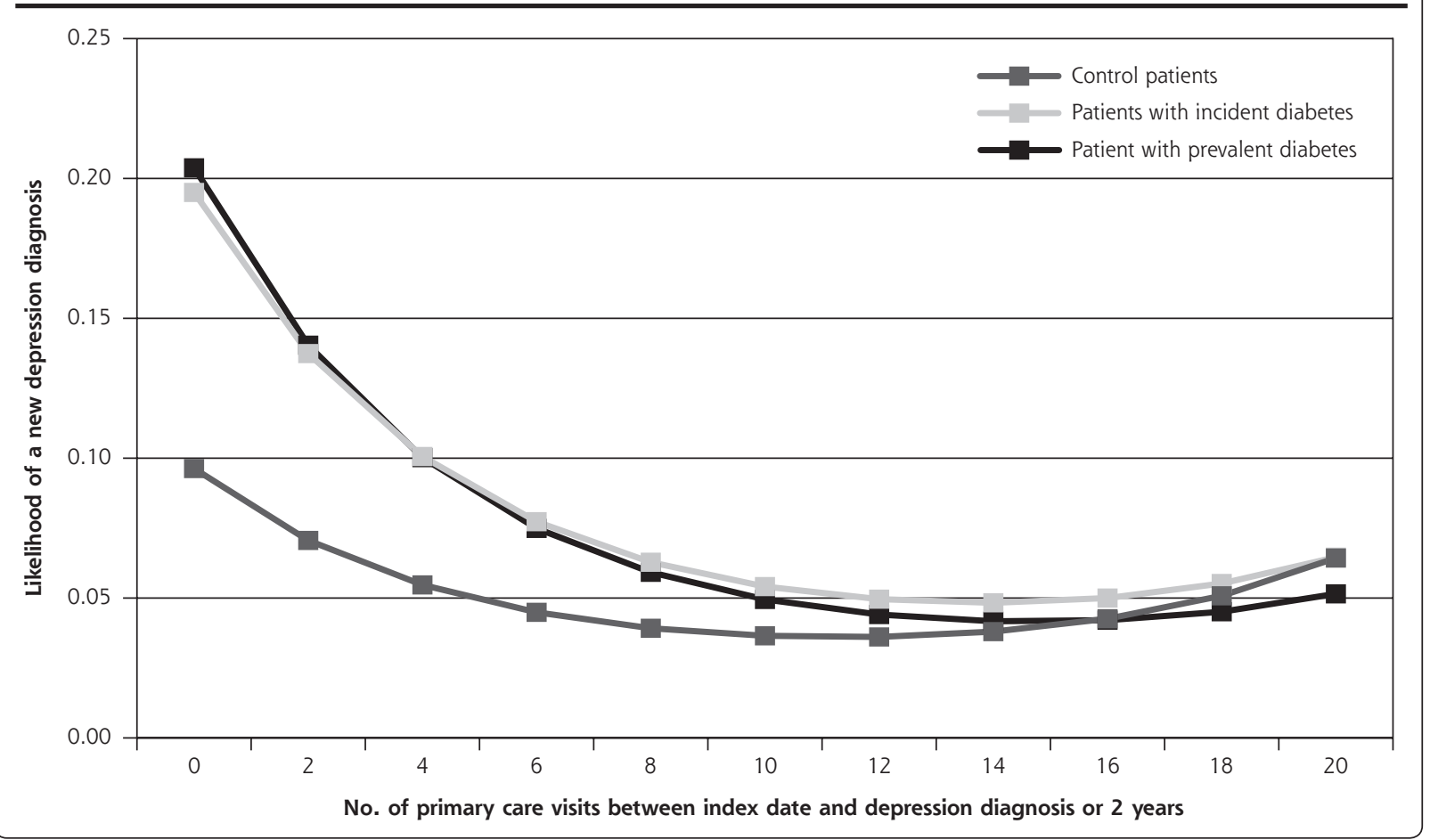

Table 3. Predictors of a New Depression Diagnosis Among Patients With Prevalent Diabetes Relative to Matched Nondiabetic Patients

\begin{tabular}{|c|c|c|c|c|}
\hline Parameter & $\begin{array}{c}\text { Age-Sex } \\
\text { Coefficient }^{\mathrm{a}}\end{array}$ & $P$ Value & $\begin{array}{l}\text { Age-Sex-Visit } \\
\text { Coefficient }^{\mathrm{a}}\end{array}$ & $P$ Value \\
\hline \multicolumn{5}{|l|}{ Diabetes } \\
\hline Incident & 0.577 & $<.001$ & 0.002 & .98 \\
\hline Prevalent & 0.543 & $<.001$ & -0.083 & .08 \\
\hline \multicolumn{5}{|l|}{ Age } \\
\hline Linear $^{b}$ & 0.011 & $<.001$ & 0.004 & .01 \\
\hline Quadratic & 0.0002 & .002 & 0.0002 & .009 \\
\hline Sex (male) & -0.421 & $<.001$ & -0.474 & $<.001$ \\
\hline \multicolumn{5}{|l|}{ Number of $P C$ visits } \\
\hline Linearc & -0.087 & $<.001$ & -0.088 & $<.001$ \\
\hline Quadratic & 0.008 & $<.001$ & 0.006 & $<.001$ \\
\hline Comorbidity score $\geq 1$ & 0.522 & $<.001$ & 0.544 & $<.001$ \\
\hline Enrollment $\leq 19$ months & 0.012 & .91 & -0.365 & $<.001$ \\
\hline \multicolumn{5}{|l|}{ Interactions } \\
\hline Incident diabetes * number of PC visits & -0.041 & .04 & -0.034 & .09 \\
\hline Prevalent diabetes * number of $\mathrm{PC}$ visits & -0.056 & $<.001$ & -0.040 & $<.001$ \\
\hline Incident diabetes * enrollment $\leq 19$ months & -0.054 & .80 & - & - \\
\hline Prevalent diabetes * enrollment $\leq 19$ months & -0.372 & .004 & - & - \\
\hline Number of PC visits ${ }^{*}$ comorbidity score $\geq 1$ & -0.056 & $<.001$ & -0.066 & $<.001$ \\
\hline Number of $P C$ visits * enrollment $\leq 19$ months & 0.110 & $<.001$ & 0.105 & $<.001$ \\
\hline \multicolumn{5}{|l|}{ Statistics } \\
\hline Intercept & -3.056 & - & -2.315 & - \\
\hline Likelihood ratio $\chi^{2}$ & 673.19 & $<.001$ & 657.94 & $<.001$ \\
\hline C statistic & 0.655 & .25 & 0.645 & .18 \\
\hline Hosmer-Lemeshow $\chi^{2}$ & 10.20 & - & 11.39 & - \\
\hline
\end{tabular}


significantly more likely to have a new depression diagnosis than matched control patients (odds ratio [OR] $=1.46,95 \%$ confidence interval $[\mathrm{CI}], 1.19-1.80)$, but this relationship diminished when patients made more than 10 primary care visits $(\mathrm{OR}=0.95,95 \% \mathrm{CI}, 0.77$ 1.17). Both the patients with prevalent diabetes and the patients with incident diabetes were more likely than the age-sex-matched nondiabetic patients to have a new depression diagnosis during the at-risk period, but this effect diminished as diabetic patients accrued more primary care visits (Figure 1). The interaction between a patient's diabetes status and number of primary care visits also emerged when comparing prevalent and incident diabetes patients with their age-sex-visit matches, $\left(\chi_{2}^{2}=18.00, P<.001\right)$, but showed a different pattern of results (Figure 2). The likelihood of a depression diagnosis was similar among diabetic patients and their matches, and decreased with more visits.

Regardless of the comparison group, men were less likely than women to have a depression diagnosis, the likelihood of depression increased with age, and there were significant interactions between number of primary care visits and Charlson comorbidity score, and between number of primary care visits and enrollment (Table 3). In both models, patients with a Charlson comorbidity score of 1 or higher were more likely to have a depression diagnosis, but this difference diminished as the number of primary care visits increased so that once patients accrued about 8 such visits, those with a higher Charlson score were no more likely than those with a score of 0 to have a depression diagnosis. Also in both models, a greater number of primary care visits was associated with a decreased likelihood of a depression diagnosis among those with full enrollment.

In the logistic regression analysis predicting a new depression diagnosis among the patients with incident diabetes relative to their age-sex-matched nondiabetic counterparts, there was no simple relationship between a patient's diabetes status and depression, or between primary care visits and depression (Table 4). Diabetes status was related to depression only in interactions with Charlson comorbidity scores $\left(\chi_{2}^{2}=6.27, P<.02\right)$, and with enrollment $\left(\chi_{2}^{2}=4.71, P=.03\right)$. Among patients with a Charlson score of 0 , those with incident diabetes had approximately twice the odds of a depression diagnosis as their age-sex-matched nondiabetic peers $(\mathrm{OR}=2.06)$. In contrast, there was no increase in odds among patients with a Charlson score of 1 or higher $(\mathrm{OR}=1.00)$.

Finally, with additional matching for number of primary care visits, patients with prevalent diabetes mellitus and few primary care visits were more likely to have a new diagnosis of depression than those in the control group $(\mathrm{OR}=1.32,95 \% \mathrm{CI}, 1.07-1.63)$, but this relationship diminished and reversed when patients made more than 4 primary care visits $(\mathrm{OR}=0.99,95 \%$ CI, 0.80-1.23).

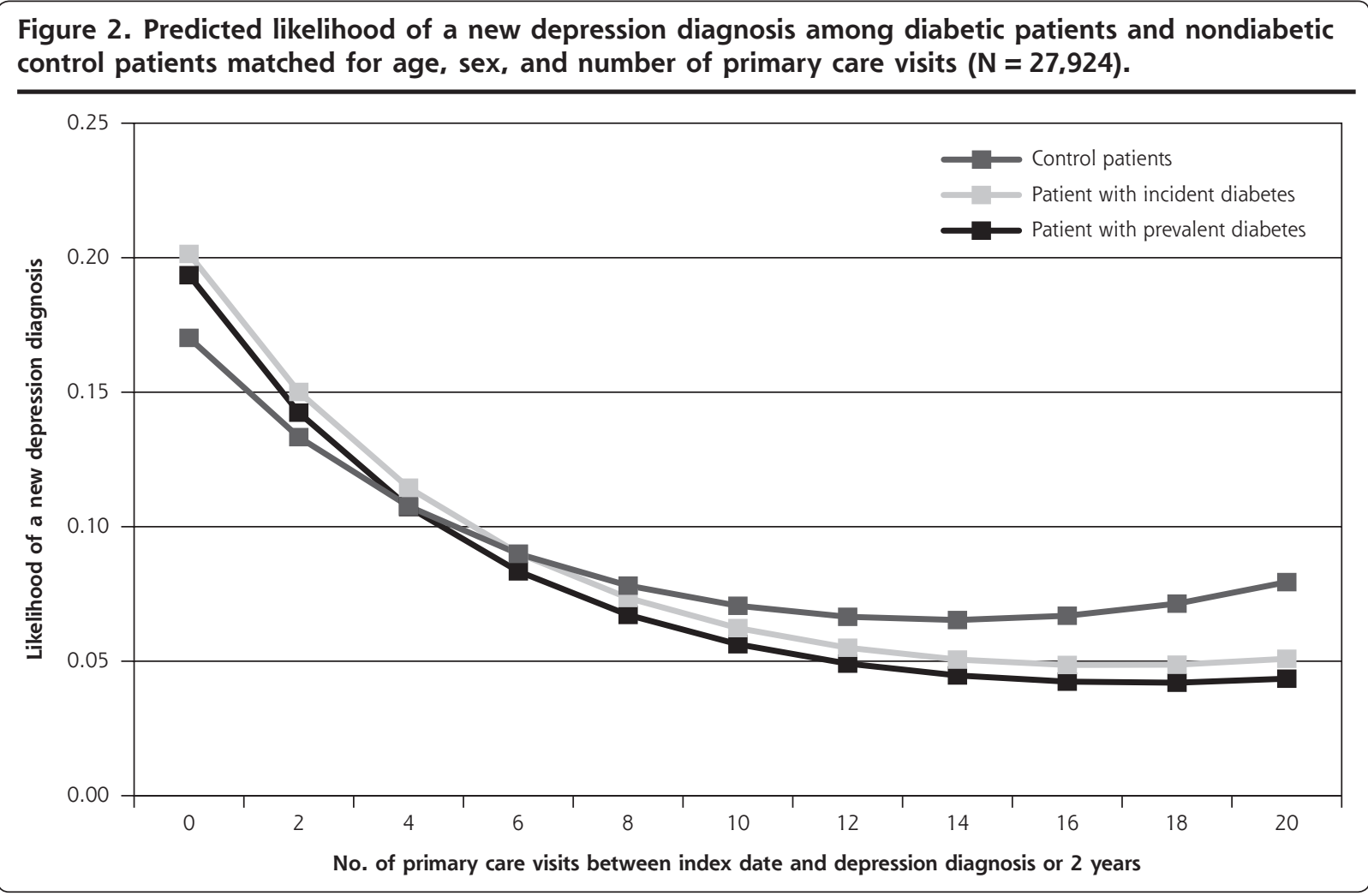




\begin{tabular}{|c|c|c|c|c|}
\hline Parameter & $\begin{array}{l}\text { Age-Sex } \\
\text { Coefficient }\end{array}$ & $P$ Value & $\begin{array}{l}\text { Age-Sex-Visits } \\
\text { Coefficient }^{a}\end{array}$ & $P$ Value \\
\hline Incident diabetes & 0.724 & $<.001$ & 0.113 & .23 \\
\hline \multicolumn{5}{|l|}{ Age } \\
\hline Linear $^{b}$ & 0.007 & .04 & 0.002 & .59 \\
\hline Quadratic & 0.0004 & .04 & 0.00008 & .64 \\
\hline Sex (male) & -0.488 & $<.001$ & -0.570 & $<.001$ \\
\hline \multicolumn{5}{|l|}{ Number of $P C$ visits } \\
\hline Linearc & -0.119 & $<.001$ & -0.119 & $<.001$ \\
\hline Quadratic & 0.008 & $<.001$ & 0.006 & $<.001$ \\
\hline Comorbidity score $\geq 1$ & 1.061 & $<.001$ & 0.496 & $<.001$ \\
\hline Enrollment $\leq 19$ months & -0.701 & .01 & -0.222 & .14 \\
\hline \multicolumn{5}{|l|}{ Interactions } \\
\hline Incident diabetes * comorbidity score $\geq 1$ & -0.723 & .01 & - & - \\
\hline Incident diabetes * enrollment $\leq 19$ months & 0.628 & .03 & - & - \\
\hline Number of $\mathrm{PC}$ visits * enrollment $\leq 19$ months & 0.094 & .004 & 0.106 & $<.001$ \\
\hline Intercept & -3.032 & - & -2.269 & - \\
\hline
\end{tabular}

\section{DISCUSSION}

The results of this study deepen our understanding of the complex interplay of depression and diabetes, and challenge to some extent the conventionally accepted view that diabetes substantially increases the risk of depression. ${ }^{10-12,18}$ Although our data confirm that diabetes is associated with a significantly higher risk of a depression diagnosis when controlling only for age and sex, additional analyses clearly show that much of this purported association is attributable to the fact that diabetic patients have more frequent contact with the medical care system than age- and sex-matched patients without diabetes. When patients are matched on number of outpatient visits, differences in depression diagnosis among those with and without diabetes are very much diminished.

The higher relative risk of a depression diagnosis among diabetic patients reported in some previous studies may have been mediated in part by the burden of comorbid conditions associated with diabetes, and in part by the increased numbers of outpatient visits those with diabetes have, relative to their nondiabetic counterparts. ${ }^{19}$ In addition, variation in sources of data, lack of severity indicators for both depression and diabetes, lifestyle factors, and variation in treatment of both diabetes and depression may contribute to differences in findings across studies. ${ }^{20}$

Our results are consistent with the hypothesis that having a diagnosed chronic condition increases the frequency of a depression diagnosis. Our data sug- gest, however, that patients with diabetes are no more affected by this susceptibility than patients with other chronic conditions who have frequent outpatient visits. Patients with diabetes, as well as those with many other chronic conditions, must deal with the psychosocial impact of adjusting to a chronic disease diagnosis or to news of progressive complications over time. ${ }^{21-24}$ This hypothesis is also supported by observation of high rates of depression in populations with other chronic illnesses, such as patients with cancer or heart disease.

The number of visits influences the likelihood of a depression diagnosis to a significant degree in both patients with and patients without diabetes. Figures 1 and 2 demonstrate that the likelihood of this diagnosis is highest in those with relatively few outpatient visits. These data might indicate that primary care clinicians are good at recognizing depression after only a few visits. Other explanations are possible, however; perhaps physicians who do not recognize depression early are unlikely to diagnose it later. We do not have sufficient data to explore these competing hypotheses, but they merit attention in future research.

The interpretation of our findings is limited by several factors. Ascertainment of depression was based on diagnostic codes and drug prescriptions, rather than on formal mental status examinations done by researchers. But we previously validated this method of depression identification and noted that its positive predictive value was about 0.95 , indicating that most of the patients identified as having depression actually did 
have it. ${ }^{14}$ Identification of a depression diagnosis using electronic data with reasonably high positive predictive value has some important practical advantages, even if sensitivity is low: (1) assessment of large numbers of patients becomes feasible, (2) assessment may be repeated periodically to identify new cases, thus offsetting some of the low sensitivity, (3) data loss due to lack of response would be minimal or nonexistent, in contrast to what would occur if depression were assessed using interviews or surveys, and (4) registries could be constructed and used to guide physician actions or to invite patient involvement in treatment or relapse-prevention activities. Nonetheless, because identification of depression may vary by geography or care system, our results require replication in other settings.

Despite some study limitations, our findings are important because they deepen our understanding of the relationship of diabetes and depression, identify new hypotheses for exploration, and demonstrate the use of a reasonably accurate method of identifying those with depression diagnoses using large electronic databases. Our growing understanding of the complex interrelationships between depression and other chronic diseases ${ }^{20,24-26}$ may eventually lead to more effective care for millions of adults with multiple chronic diseases.

To read or post commentaries in response to this article, see it online at http://www.annfammed.org/cgi/content/full/7/4/328.

Key words: Diabetes mellitus; depression; incident diabetes; prevalent diabetes; population health; practice-based research; primary care

Submitted May 22, 2008; submitted, revised, October 7, 2008; accepted November 2, 2008.

Funding support: This project was supported by the National Institute of Diabetes, Digestive, and Kidney Diseases (NIDDK) through grant R01 DK06650.

\section{References}

1. Holman RR, Paul SK, Bethel MA, Matthews DR, Neil HA. 10-year follow-up of intensive glucose control in type 2 diabetes. $N$ Engl J Med. 2008;359(15)1577-1589.

2. Patel A, MacMahon S, Chalmers J, et al; ADVANCE Collaborative Group. Effects of a fixed combination of perindopril and indapamide on macrovascular and microvascular outcomes in patients with type 2 diabetes mellitus (the ADVANCE trial): a randomised controlled trial. Lancet. 2007;370(9590):829-840.

3. Pyörälä K, Pedersen TR, Kjekshus J, Faergeman O, Olsson AG, Thorgeirsson $\mathrm{G}$. Cholesterol lowering with simvastatin improves prognosis of diabetic patients with coronary heart disease. A subgroup analysis of the Scandinavian Simvastatin Survival Study (4S). Diabetes Care. 1997;20(4):614-620.

4. Gaede P, Lund-Andersen $\mathrm{H}$, Parving $\mathrm{HH}$, Pedersen O. Effect of a multifactorial intervention on mortality in type 2 diabetes. $N$ Engl J Med. 2008;358(6):580-591.

5. Callahan CM, Hui SL, Nienaber NA, Musick BS, Tierney WM. Longitudinal study of depression and health services use among elderly primary care patients. J Am Geriatr Soc. 1994;42(8):833-838.
6. Hays RD, Wells KB, Sherbourne CD, Rogers W, Spritzer K. Functioning and well-being outcomes of patients with depression compared with chronic general medical illnesses. Arch Gen Psychiatry. 1995;52(1):11-19.

7. Murphy E, Smith R, Lindesay J, Slattery J. Increased mortality rates in late-life depression. Br J Psychiatry. 1988;152:347-353.

8. Wells KB, Stewart A, Hays RD, et al. The functioning and well-being of depressed patients. Results from the Medical Outcomes Study. JAMA. 1989;262(7):914-919.

9. Whooley MA, Simon GE. Managing depression in medical outpatients. N Engl J Med. 2000;343(26):1942-1950.

10. Anderson RJ, Freedland KE, Clouse RE, Lustman PJ. The prevalence of comorbid depression in adults with diabetes: a meta-analysis. Diabetes Care. 2001;24(6):1069-1078.

11. Golden SH, Lazo M, Carnethon M, et al. Examining a bidirectional association between depressive symptoms and diabetes. JAMA. 2008;299(23):2751-2759.

12. Robinson N, Fuller JH, Edmeades SP. Depression and diabetes. Diabet Med. 1988;5(3):268-274.

13. Viinamäki $H$, Niskanen L, Uusitupa M. Mental well-being in people with non-insulin-dependent diabetes. Acta Psychiatr Scand. 1995;92(5):392-397.

14. Solberg LI, Engebretson KI, Sperl-Hillen JM, Hroscikoski MC, O'Connor PJ. Are claims data accurate enough to identify patients for performance measures or quality improvement? The case of diabetes, heart disease, and depression. Am J Med Qual. 2006;21(4):238-245.

15. Solberg LI, Crain AL, Sperl-Hillen JM, Hroscikoski MC, Engebretson $\mathrm{KI}, \mathrm{O}$ 'Connor PJ. Effect of improved primary care access on quality of depression care. Ann Fam Med. 2006;4(1):69-74.

16. Van Tilburg MA, McCaskill CC, Lane JD, et al. Depressed mood is a factor in glycemic control in type 1 diabetes. Psychosom Med. 2001;63(4):551-555.

17. Deyo RA, Cherkin DC, Ciol MA. Adapting a clinical comorbidity index for use with ICD-9-CM administrative databases. J Clin Epidemiol. 1992;45(6):613-619.

18. Lustman PJ, Anderson RJ, Freedland KE, de Groot M, Carney RM, Clouse RE. Depression and poor glycemic control: a meta-analytic review of the literature. Diabetes Care. 2000;23(7):934-942.

19. Beaulieu N, Cutler DM, Ho K, et al. The business case for diabetes disease management for managed care organizations. Forum Health Econ Policy. 2006;9(1):1-37. Manuscript 1072.

20. Rost K, Nutting P, Smith J, Coyne JC, Cooper-Patrick L, Rubenstein $\mathrm{L}$. The role of competing demands in the treatment provided primary care patients with major depression. Arch Fam Med. 2000;9(2):150-154.

21. de Groot M, Jacobson AM, Samson JA, Welch G. Glycemic control and major depression in patients with type 1 and type 2 diabetes mellitus. J Psychosom Res. 1999;46(5):425-435.

22. Talbot F, Nouwen A, Gingras J, Bélanger A, Audet J. Relations of diabetes intrusiveness and personal control to symptoms of depression among adults with diabetes. Health Psychol. 1999;18(5):537-542.

23. Palinkas LA, Barrett-Connor E, Wingard DL. Type 2 diabetes and depressive symptoms in older adults: a population-based study. Diabet Med. 1991;8(6):532-539.

24. Dunlop DD, Lyons JS, Manheim LM, Song J, Chang RW. Arthritis and heart disease as risk factors for major depression: the role of functional limitation. Med Care. 2004;42(6):502-511.

25. Hunkeler EM, Katon W, Tang L, et al. Long term outcomes from the IMPACT randomised trial for depressed elderly patients in primary care. BMJ. 2006;332(7536):259-263.

26. Katon W, Unützer J, Fan MY, et al. Cost-effectiveness and net benefit of enhanced treatment of depression for older adults with diabetes and depression. Diabetes Care. 2006;29(2):265-270. 